\title{
EL CONTROL GUBERNAMENTAL PARA EL LOGRO DE LOS OBJETIVOS NACIONALES
}

\author{
Dr. JULIO V. FLORES KONJA (*) \\ Mg. 'ADRIAN A. FLORES KONJA (**) \\ Lic. ANA M. GUTIERREZ HUBY (***)
}

La administración pública es una sección importante de la organización social moderna en su conjunto, que conforma una estructura con cuadros permanentes los que sirven para definir el buen gobierno; mediante el cumplimiento de fines sociales dentro del armazón política del Estado, en busca del bien común. Este tipo de estructura adopta la forma burocrática, por cuanto ella representa el tipo weberiano de dominación legal-racional, por ser capaz de proveernos de esos fines en la forma más eficiente. Siendo este tipo de organización estructural eminentemente racional por definición, su falta de eficiencia puede ocasionar un desvío del fin deseado debido a que el cuadro administrativo no cumple con los requisitos de modernidad, universalidad, especificidad, neutralidad afectiva y adquisición.

Dicho en otros términos, la burocracia instituida no es eficiente, y para serlo todos los niveles de su estructura deben estar sujetos a controles razonables consonantes con la Ley por lo que, cuando la conducta de sus miembros no responde a modelos de modernidad para la época de crisis, se debe establecer metas, objetivos y fines precisos en un marco de capacitación de cada nivel con la correspondiente modernización de la infraestructura. Caso contrario, la administración pública resulta ser un tipo especial de burocracia, donde la falta de eficiencia puede ser vista por poseer objetivos y fines con un elevado grado de generalidad; es decir, escasa especificidad, cuyo resultado tiene por lo general, efecto directo insignificante, en relación con el beneficio económico esperado por la Nación.

Por las características enunciadas, para que la administración pública pueda gerenciar controles eficaces, tendrá que:

1. Evaluar situaciones concretas y específicas por actividades económicas y sociales que le permitan consolidar su visión sobre la situación global del contexto y determinar todos los obstáculos nodales que dificulten o impidan el desarrollo de la eficiencia, como premisas de valor a niveles específicos de la sociedad y la organización social en su conjunto, debiéndose instituir las bases y principios necesarios que se despredan de la evaluación específica referida y sirvan de orientación sólida para

(*) Decano y Docente Principal de la Facultad de Ciencias Contables de la UNMSM.

(**) Docente Principal de la Facultad de Ciencias Contables de la UNMSM.

$\left({ }^{* * *}\right)$ Docente Asociado de la Facultad de Ciencias Contables de la UNMSM. 
el funcionamiento armonioso de la estructura administrativa.

2. Analizar la situación de cada organización estatal mejorando la infraestructura, material y los recursos humanos conducentes al aumento de la racionalidad, modificando estructuras y procesos y aplicando métodos y tecnologías que los induzcan permanentemente hacia los resultados que habrán de ser fijados, de acuerdo a las necesidades más críticas.

El Control Gubernamental, de acuerdo a lo dispuesto por el Art. $5^{\circ}$ de la Ley del Sistema Nacional de Control, Decreto Ley $\mathrm{N}^{\circ} 26162$ del 30.DIC.92, consiste en la verificación periódica del resultado de la gestión pública, a la luz del grado de eficiencia, eficacia, transparencia y economía que hayan exhibido en el uso de los recursos públicos, así como del cumplimiento por las entidades de las normas legales y de los lineamientos de política y planes de acción. Evalúa la eficacia de los sistemas de administración, control y establece las causas de los errores e irregularidades para recomendar las medidas correctivas.

El control que ejerce el Sistema es interno y externo; pero, siempre selectivo y posterior.

El control interno previo compete exclusivamente a las entidades que ejecutan la gestión debiendo, para ello, crear sus normas internas de control en base a las normas generales y reglamentarias vigentes que le sean aplicables, en función de su propia organización.

El control interno posterior es ejercido por los responsables superiores del servidor o funcionario ejecutor en función de los procedimientos de control dados por el titular de la misma respecto de los resultados de las operaciones bajo su competencia y por el auditor en función a sus planes y programas anuales. Este control debe evaluar no sólo los aspectos administrativos del uso de los recursos; sino, evaluar la gestión en función de las metas y programas trazados.

Los órganos internos de control, o Auditoría Interna, realizan control posterior mediante auditorías y exámenes especiales, para evaluar la medida en que las normas internas, lineamientos y procedimientos, puestos en práctica por las entidades, han sido eficaces para salvaguardar sus activos, asegurar la razonabilidad de su información contable, tender a una gestión eficiente que cumpla las metas y programas trazados, así como a la obtención de los resultados previstos.

El control externo consiste en el conjunto de políticas, normas, métodos y procedimientos técnicos aplicados por la Contraloría General de la República y/o por los órganos del Sistema que ejercen control gubernamental y las sociedades de auditoría independiente que ésta designa y se contrata para evaluar la gestión, la capacitación y el uso de los recursos públicos por ellas. Se efectúa mediante auditorías y exámenes especiales.

Por lo tanto, para el logro de los objetivos nacionales es necesario que la función pública se desarrolle en términos de integridad, transparencia y responsabilidad; consolidando la conducta honesta de los funcionarios y servidores, en la cual prime el interés público sobre el particular, honrando la confianza que la ciudadanía ha puesto en las instituciones gubernamentales así como del personal que labora en ellas.

Las diferentes autoridades del gobierno y la ciudadanía necesitan información respecto al desarrollo de la gestión y el ejercicio de la función pública, para evaluar la integridad, el desempeño y el logro de los 
objetivos y metas institucionales, por lo cual le corresponde a los funcionarios y servidores, en todos sus niveles, rendir cuenta de sus responsabilidades funcionales.

Cultivando la integridad lograremos personas que mantengan principios morales sólidos y vivan en un marco de valores. La ética está conformada por valores morales que permiten a la persona adoptar decisiones $\mathrm{y}$ tener un comportamiento correcto en las actividades que le corresponden cumplir en la entidad.

En los últimos años se han evidenciado considerables actos irregulares y presuntos delitos en contra del Estado en la administración pública, por lo que la Contraloría General de la República para el año 2002 está demandando un control más exhaustivo del uso de los recursos públicos, incidiendo en las áreas críticas de gestión sensibles a la corrupción, con el fin de atender la creciente demanda de fiscalización de la sociedad, en su conjunto, y del Congreso de la República en particular, planteándose los objetivos estratégicos de "Mejorar y Modernizar el Control Gubernamental", "Promover la Lucha contra la Corrupción Administrativa" y "Fortalecer el Sistema Nacional de Control", acorde con los Objetivos Nacionales.

Cuando hablamos de los Objetivos Nacionales, nos referimos al Planeamiento Estratégico Multianual de los Sectores para los años 2001-2005 (aprobado por D.S. $\mathrm{N}^{\circ}$ 108-2000-EF) que fue un primer esfuerzo del Sector Público y, posteriormente, se elaboró el Planeamiento Estratégico Multianual de los Sectores para los años 2002-2006 (aprobado por D.S. N ${ }^{\circ} 187$ 2001), cuyo Objetivo General del Gobierno es alcanzar altas tasas de crecimiento económico con equidad, que generen riqueza e igualdad de oportunidades para todos, disminuyendo la pobreza extrema, la desi- gualdad y la exclusión social, respetando el estado de derecho, creando condiciones para el acceso universal a lajusticia, propiciando la transparencia de los actos de gobierno y motivando una cultura de fiscalización y control social en la ciudadanía; promoviendo la inversión y el desarrollo sostenible, con énfasis en el desarrollo productivo del sector agropecuario, el turismo y la construcción, así como la producción exportable de la pequeña y mediana empresa; fomentando la generación de empleo adecuado en el sector privado (Cuadro en anexo adjunto).

Todas estas metas se lograrán con una gestión pública eficiente y austera, sobre la base de una estructura organizacional del sector público reformado, con claras competencias y responsabilidades de cada uno de los órganos nacionales y subnacionales de gobierno en el marco de un proceso de descentralización del poder central y el fortalecimiento del tejido social y las capacidades institucionales en cada provincia, como célula básica del desarrollo social y productivo del país.

Este proceso requiere, necesariamente, de una nueva carrera pública administrativa y la aplicación de estrategias contractuales de gestión, enfocadas a las funciones primordiales del Estado y en la cual, la probidad, programación, evaluación, rendición de cuentas y activa participación de la ciudadanía sean fundamentos esenciales.

El concepto de la rendición de cuentas en la administración pública se encuentra fuertemente vinculado al concepto de la misión institucional que corresponde a cada entidad pública. En efecto, la misión es el fundamento que justifica la existencia de las entidades creadas para atender la satisfacción de las necesidades colectivas, como puede ser un ministerio, una corporación, una empresa, un municipio. Cada una de ellas 
tiene una misión específica que debe ser cumplida para justificar su existencia, su razón de ser. Para que estas entidades públicas cumplan su misión deben ser gestionadas por servidores y funcionarios públicos que cumplan el rol de administradores de tales entidades, recibiendo para tal fin un conjunto de recursos y bienes, así como las atribuciones necesarias para que puedan cumplir su rol de manera apropiada. $\mathrm{Al}$ asumir este rol, los administradores asumen también la responsabilidad de rendir cuenta; es decir, mostrar la forma en que se ha cumplido la misión.

La muestra o exposición de los resultados de la gestión debe orientarse, necesariamente, a demostrar y explicar el grado en que se cumple la misión encomendada a la entidad de la que se trate. Esta afirmación presupone la existencia de una misión, unos objetivos, una estrategia y unas metas claramente definidos, aprobados y difundidos (Plan Estratégico y Plan Operativo). No resulta razonable proponer rendición de cuentas de hechos que no reúnan estas condiciones. La rendición de cuentas requiere la existencia de normas y procedimientos que conduzcan de una manera razonada y técnica, a determinar su aprobación o desaprobación.

La rendición de cuentas no puede ser concebida como un mero hecho formal que se limita a la presentación de determinada documentación, para tramitar su integración y consolidación. La finalidad de la rendición de cuentas tiene que ser, necesariamente, su aprobación o desaprobación a nivel institucional, para que genere iniciativas que conduzcan a optimizar o mejorar el desempeño de la entidad rindente. La integración y consolidación de las rendiciones de cuentas tiene la finalidad complementaria de mostrar los resultados económico-financieros de la administración pública a nivel global o marco administrativo. En cierta forma, esta integra- ción y consolidación representa la rendición de cuentas de un gobierno, respecto de su gestión económica y financiera.

Las actuales corrientes de opinión se orientan a postular que el fin que se busca cumplir, mediante la rendición de cuentas, es el de promover la calidad de la administración pública, y a través de esta vía, alcanzar satisfactoriamente el fin del Estado, que es el bienestar común.

Asimismo, para reforzar la lucha contra la corrupción en el país se institucionalizó la Comisión Nacional contra la Corrupción, cuya finalidad es contribuir a construir una cultura de moralización y promoción de la ética y transparencia en la gestión pública, tarea que se logrará si, efectivamente, se produce un cambio profundo de actitud de la población, especialmente en la ética y el manejo de la función pública. Con respecto al gasto público, apunta a un fortalecimiento de la eficiencia operativa del Estado, a la transparencia en las decisiones de carácter jurídico, económico y financiero, entre otros la adjudicación de contratos, en todo lo cual el Sistema Nacional de Control cumple un rol fundamental para el logro de los grandes objetivos nacionales y el rumbo que el Perú ha de seguir hacia su visión de futuro para fortalecer nuestra sociedad hacia el bien común. 
1. Fortalecer el Sistema Nacional de Control para la fiscalización del uso de los recursos del Estado a través de la implementación de mecanismos y procedimientos que contribuyan a evaluar el grado de cumplimiento de los objetivos nacionales.

2. Necesidad de optimizar las acciones de control previo, concurrente y posterior en las Entidades del Sector Público, a fin de evitar la corrupción en el país; y que las desviaciones que se detecten sean objeto de acciones correctivas oportunas.

3. Necesidad de difusión educativa en todos los niveles del Sector Público y de la ciudadanía en general sobre la importancia, alcance, atribuciones y responsabilidades que son de competencia del Sistema Nacional de Control.

4. Fiscalizar oportunamente a través de los órganos competentes del Sistema Nacional de Control, los ingresos y gastos del Estado, a fin de garantizar la transparencia, propiedad y legalidad de los mismos.

5. Motivar la conducta honesta de los funcionarios y servidores, en la cual prime el interés nacional sobre el particular, honrando la confianza que la ciudadanía ha puesto en las instituciones gubernamentales; así. como en el personal que labora en ellas.

6. Es necesario que el Contralor General de la República haga de conocimiento público, en forma semestral, los resultados emergentes de las acciones de fiscalización y control que realizan los organismos conformantes del Sistema Nacional de Control. 


\begin{tabular}{|c|c|c|c|}
\hline 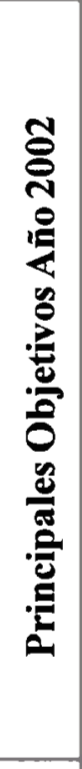 & 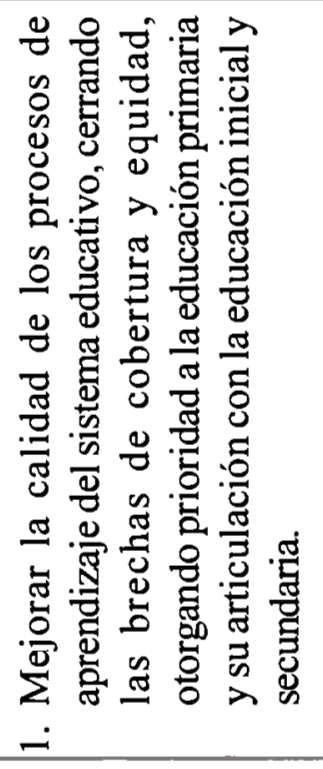 & 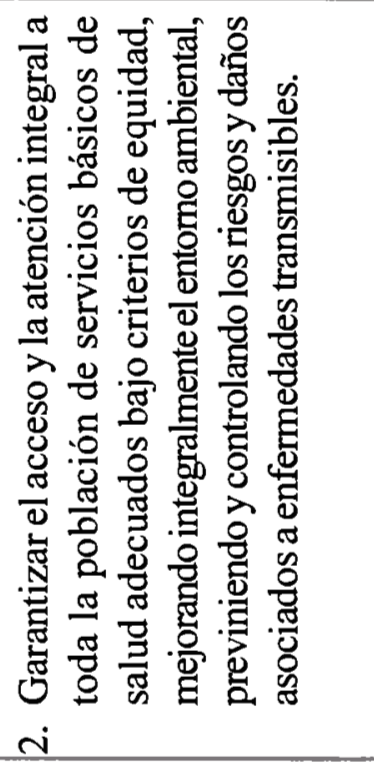 & 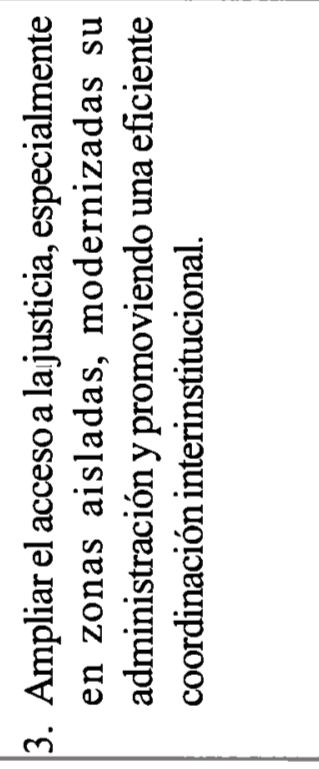 \\
\hline 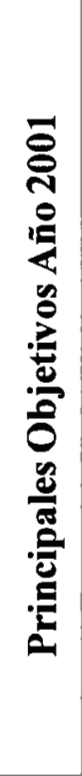 & 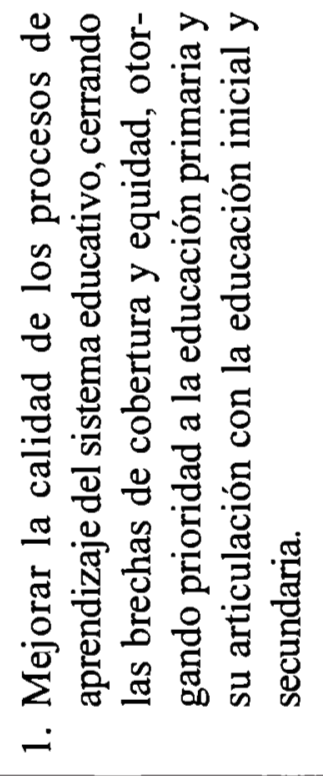 & 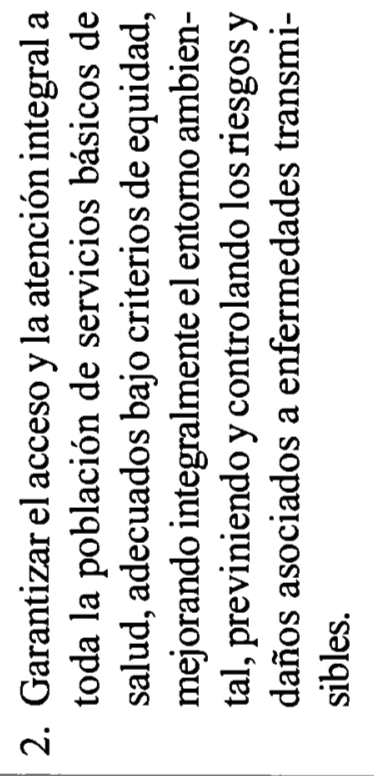 & 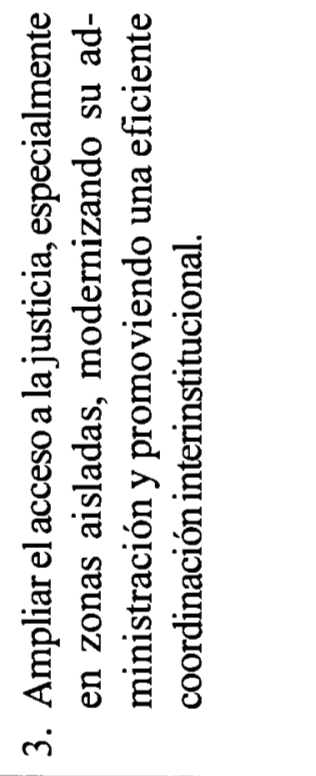 \\
\hline 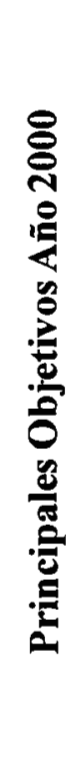 & 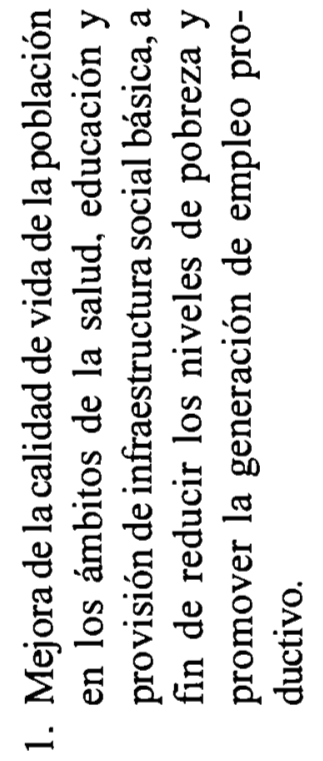 & 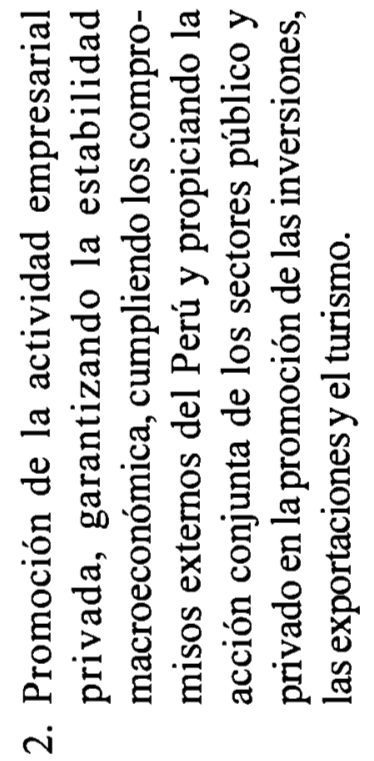 & 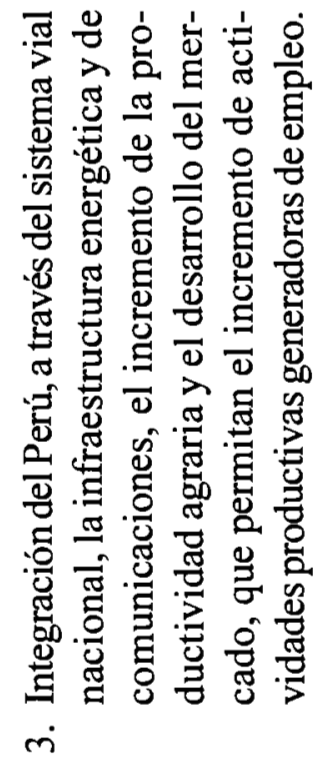 \\
\hline
\end{tabular}




\begin{tabular}{|c|c|c|c|}
\hline 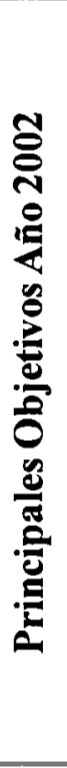 & 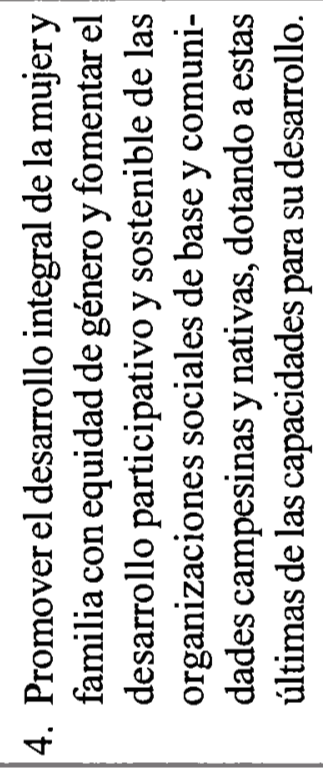 & 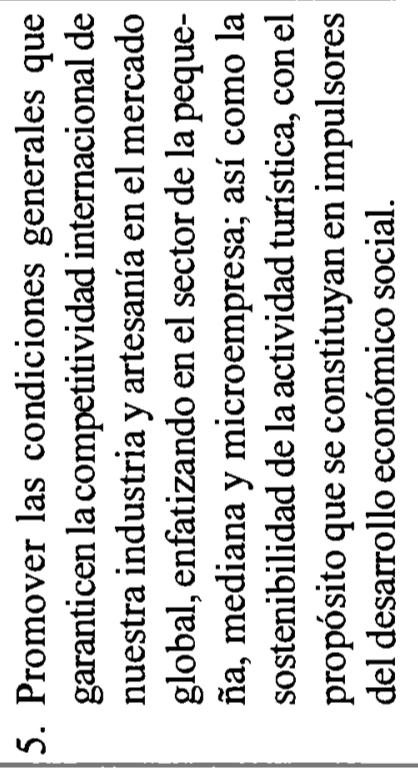 & 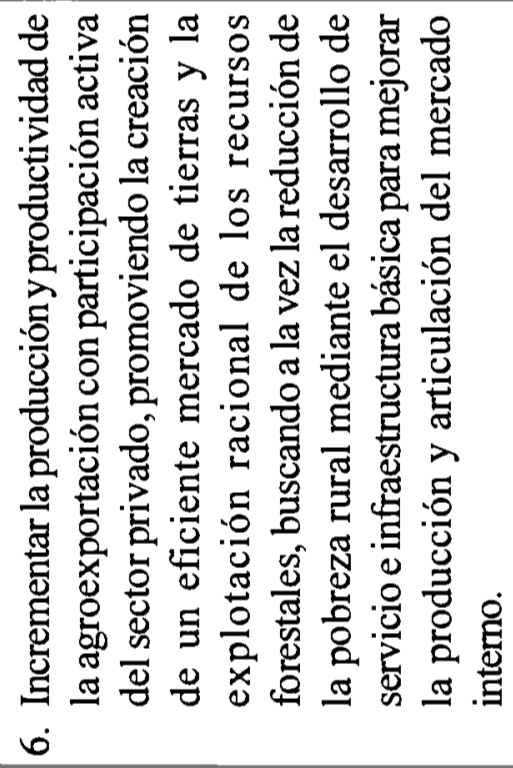 \\
\hline 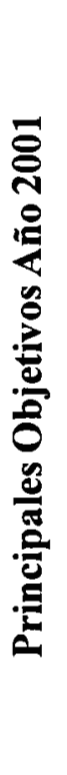 & 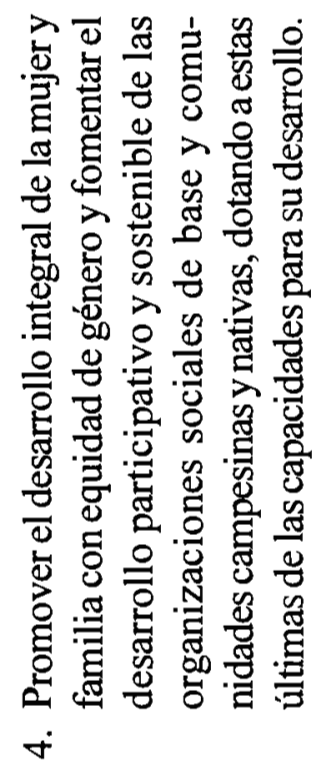 & 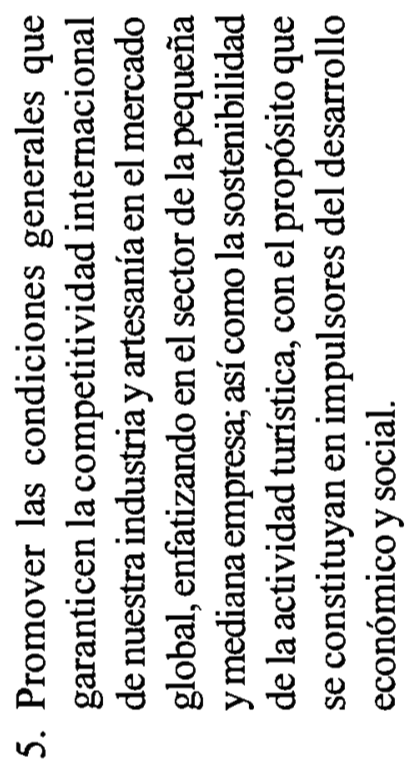 & 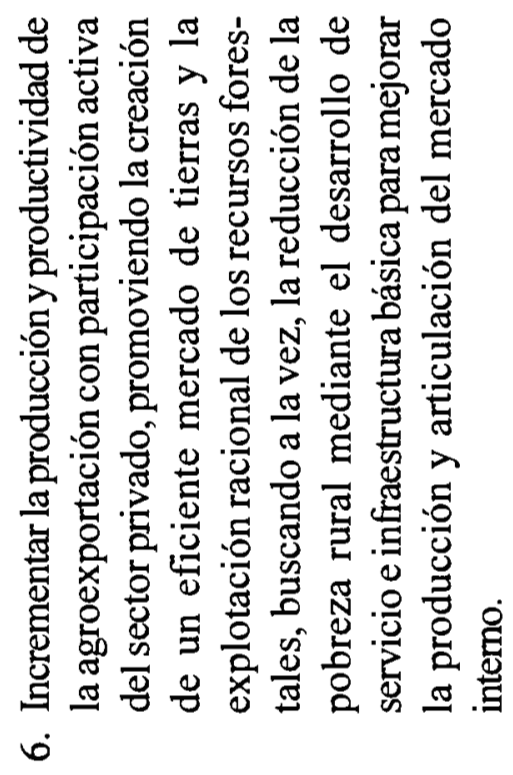 \\
\hline 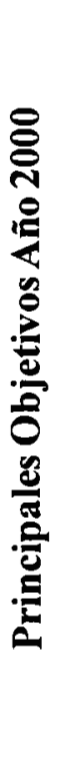 & 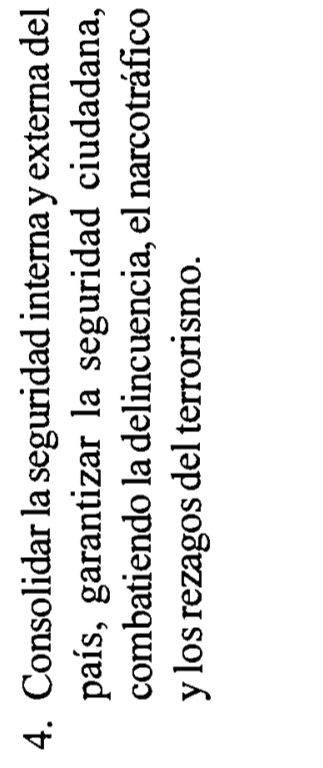 & & 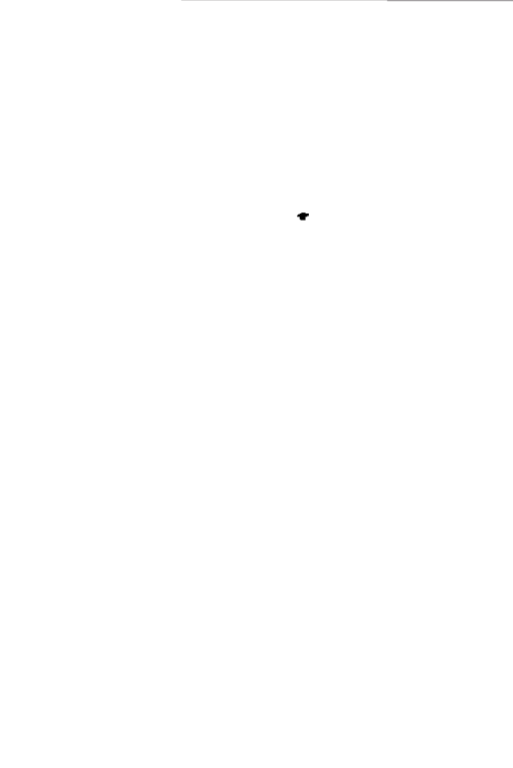 \\
\hline
\end{tabular}




\begin{tabular}{|c|c|c|c|c|}
\hline 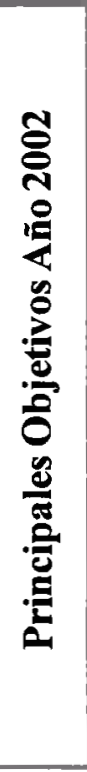 & 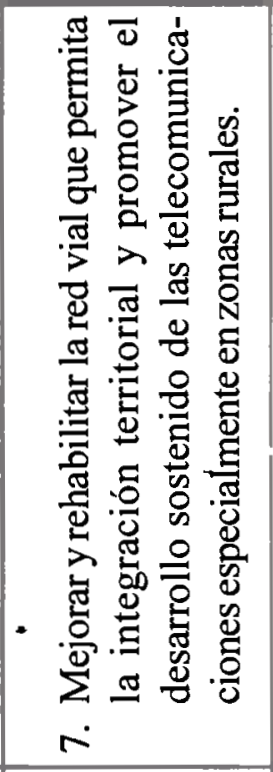 & 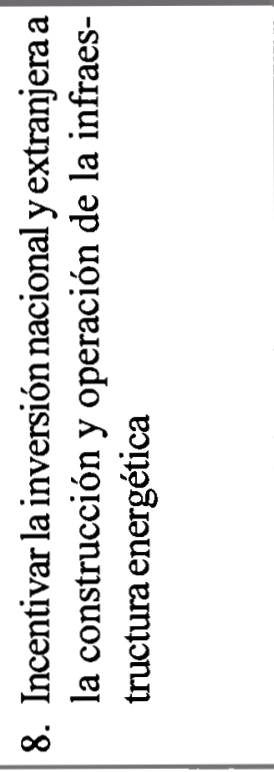 & 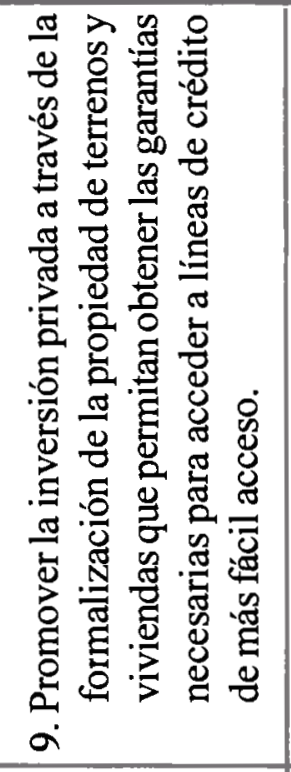 & 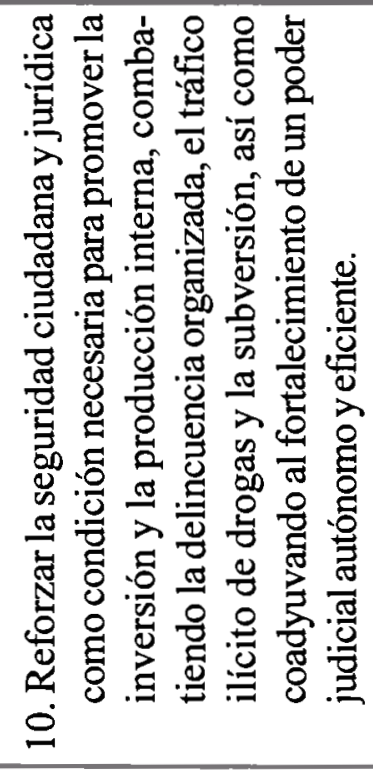 \\
\hline 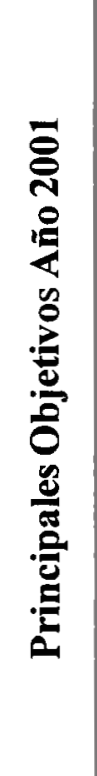 & 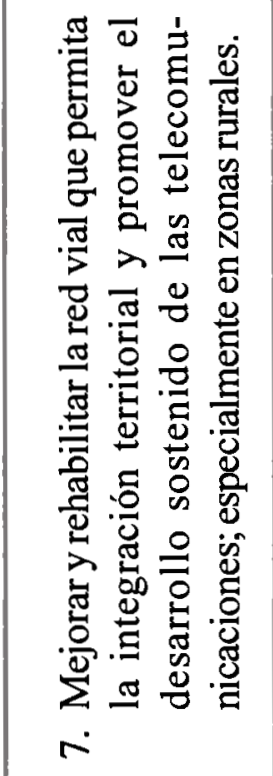 & 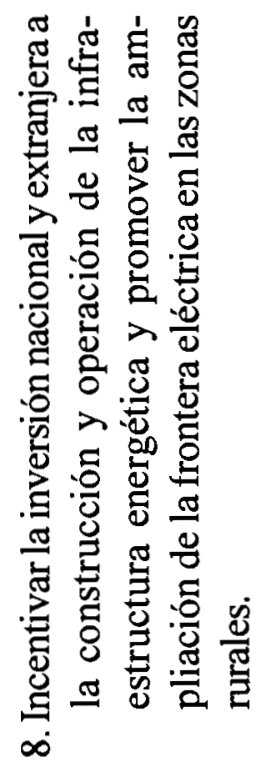 & 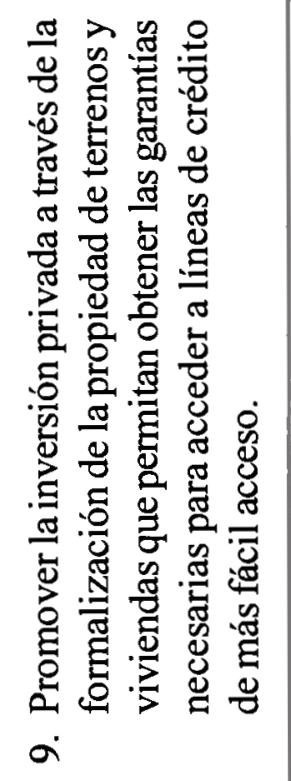 & 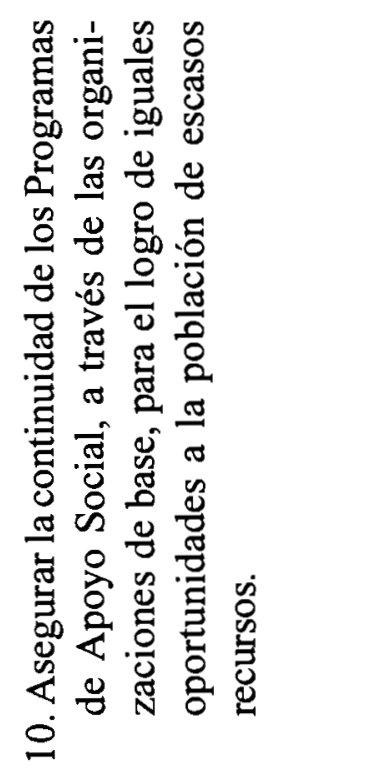 \\
\hline 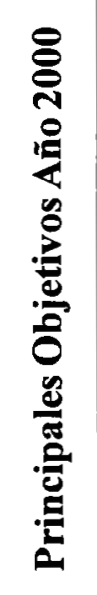 & & & & \\
\hline
\end{tabular}




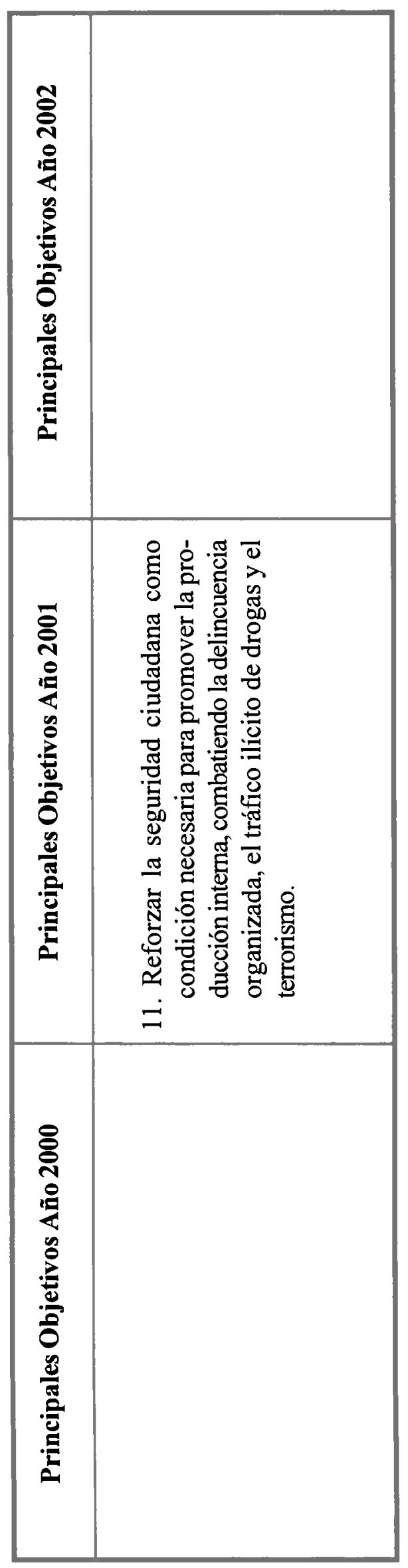

